\title{
Cochlear Implant Reliability: On the Reporting of Rates of Revision Surgery
}

\author{
Graham O’Neill $^{1} \cdot$ Neil S. Tolley ${ }^{1}$
}

Received: 10 November 2019/Accepted: 18 January 2020/Published online: 1 April 2020

(C) The Author(s) 2020

\begin{abstract}
The aim of this study was to determine the magnitude of the risks associated with cochlear implantation. Results from a pool of thirty clinical studies involving cochlear implantation in over 6300 children were obtained from an internet search. The relevant data were transformed to a common time base (patient time) to allow an evaluation of events following implantation. The main outcome measure was cumulative survival probability for all-cause revision surgery. Over 10 years this was estimated to be 0.71 . Thus, at 10 years post-implantation close to $30 \%$ of children with unilateral implants will have undergone revision surgery. This figure is considerably greater than that commonly reported for overall revision rates and illustrates the importance of interpreting results with respect to the relevant time frame. When non and lowuse is incorporated into the analysis the above figure rises to about $37 \%$ of children affected. The findings raise concerns about the information provided to both individuals and regulatory bodies regarding the risks associated with cochlear implantation. The consequences for bilateral implantation are apparent. Our recommendations are i) a full disclosure to parents and children of the true magnitude of the risks and ii) for a body with significant expertise in reliability and systems engineering, and no conflicts of interest, to play a major role in the regulatory management of this service.
\end{abstract}

Keywords Implanted device - Complications · Reliability · Revision surgery $\cdot$ Health service

Neil S. Tolley

n.tolley@imperial.ac.uk

1 Department of Otolaryngology, Head and Neck Surgery, St Mary's Hospital, London, UK

\section{Introduction}

Many thousands of children have undergone cochlear implant surgery worldwide with bilateral implants being increasingly prescribed in more recent years. The intervention is often described as safe and reliable. However, rates of revision surgery are almost exclusively reported as an 'overall' figure which, because of the staggered-entry nature of the studies, is an incorrect and misleading metric. The accrual of patients over the course of a study masks both the magnitude and temporal characteristics of variables of interest since standard statistical measures based upon the whole group contain time-related biases. Lifetable (actuarial) or Kaplan-Meier methods can be used to accommodate these effects but even here serious errors can be generated under certain conditions [1-4]. Regarding cochlear implant revision surgery, published papers contain information on both overall incidence rates and surgical details but time relevant information is, in the main, limited. Although efforts have been made to improve reporting standards, comparing results from different studies and sources is difficult and considered by some to be an almost impossible task $[5,6]$. This is disconcerting because it indicates an inability to determine reliability with confidence, whether of the implant alone or of the intervention as a whole. The only study we are aware of to seriously address this problem is that of Wang et al. [7] which involved analysis of revision surgery in their own patient population. However, the effect of implant recalls because of high failure rates is not well represented. For example, the high failure rate of the Cochlear ${ }^{\circledR}$ Nucleus C1500 series (released 2009, recalled 2011) is not reflected in the clinical results (their Fig. 4). Also, the recall of an implant by Advanced Bionics in 2010 was not represented since the authors report only using one device from this 
manufacturer. In order to obtain a wider body of evidence, we describe in this paper how results gleaned from a pool of clinical studies were transformed to a common time base to allow a better evaluation of events following cochlear implantation and hence a better evaluation of reliability.

\section{Methods}

The study primarily concerns implantation in children. Also, the terms 'reliability' and 'failure' are not confined to hardware or technical issues but relate to any problem associated with cochlear implantation necessitating revision surgery under general anaesthesia and also to nonuse- a fair description of failure, at least from the child's point of view. The method used for analysis is to obtain the failure characteristics of each of the components separately and then combine them to obtain the failure, or unreliability, function $\mathrm{F}(\mathrm{t})$. The reliability (survival) probability $R(t)$ is then $R(t)=1-F(t)$.

\section{Data Search}

Numerous papers and abstracts were obtained from the internet using keywords of 'cochlear implantation' with 'paediatric', 'revision surgery' and 'reimplantation'. These were then filtered as described by the flowchart below to leave 30 studies suitable for analysis.

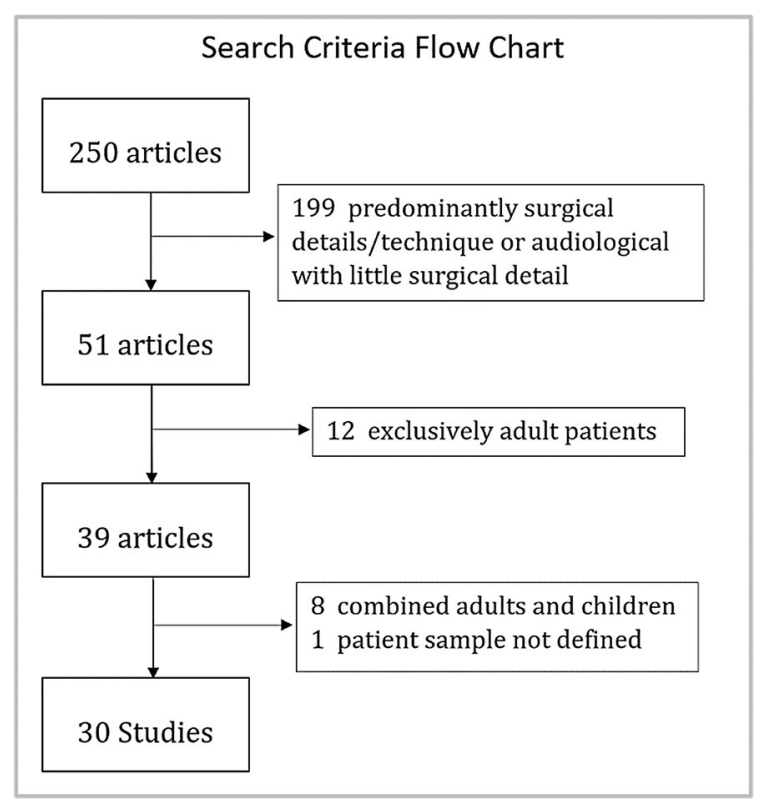

Since longer study lengths usually involve complicating factors such as increasing numbers of patients likely to be lost to follow-up, electing to have device up-grades and/or becoming non-users [8,9], studies of over 17 years duration were excluded for the calculations described above. Out of an initial 250 articles, 199 were either predominantly surgical details/technique or audiological with little surgical detail. Of the remaining 51 articles, 12 involved exclusively adult patients, leaving 39 articles of which we obtained 37 full papers, 1 conference abstract and 1 newsletter. Of these, 8 were combined results (adults and children) and 1 did not define the patient sample. This left thirty studies, with study lengths of up to 17 years and involving over 6300 children. The earliest start date was 1984 with a study length of 11 years; the latest end date was 2016 with a study length of 14 years. No attempt was made to conduct a device specific analysis. In the allocation to specific categories, we took a conservative approach and the following assumptions made as described below:

1. Where information was reported for 'explantation without reimplantation', but not included in the overall results, we adjusted the numbers to include all reported explantations.

2. Where numbers for 'explantation without reimplantation' were not reported we assumed that total explantations was equal to the number of reimplantations.

3. In cases of post-operative infection requiring explantation, reimplantation is usually performed at a later date. That is, rates reported for reimplantation underestimate the true surgical rates relating to these cases. We were unable to adjust for this in our analysis of revision surgery where the relevant information was not provided. This also applied to multiple operations for complications not involving reimplantation.

4. Studies involving both children and adults did not state the start date for implantation in children. We were able to make an adjustment for two studies from additional information where the paediatric programme started after that for adults. For the rest we assumed that the implantation periods were the same.

5. We based our calculations on implant numbers rather than on the number of children unless only the latter was available (for studies where a proportion of children have bilateral implants, the failure rate based upon implant numbers is lower than the failure rate per child).

\section{Theoretical Considerations}

For the purpose of this study revision surgery is categorized into surgery involving device explantation (e.g. device fault or medical/surgical complications necessitating device removal) and surgery which does not involve explantation (e.g. medical/surgical complications or device movement). This can be expressed as: 
$R E V_{c}(t)=E X P_{c}(t)+S U R_{c}(t)$

where for ' $t$ ' years (patient time) measured from the time of implantation at time $\mathrm{t}=0$,

$R E V_{c}(t)$ is the cumulative all-cause revision surgery (\%)

$=100 \times\left(\frac{\text { number of revisions }}{\text { number of implants }}\right)$

$\operatorname{EXP}(t)$ is the cumulative surgery involving explantation

$=100 \times\left(\frac{\text { number of explantations }}{\text { number of implants }}\right)$

$\operatorname{SUR}_{c}(t)$ is the cumulative surgery involving everything other than explantation (\%)

$=100 \times\left(\frac{\text { number of operations other than explantation }}{\text { number of implants }}\right)$

The extent to which the accrual of patients over the study period affects the calculation of cumulative explantation percentage is shown in Fig. 1. The analysis assumes an increasing accrual rate over the study period which seems reasonable given the information available [10-12]. Details of the construction of the graphs are given in "Appendix 1". Results from follow-up studies were used in their original form i.e. not adjusted for 'staggered entry' as described above, and identified where appropriate in the presentation of results.

\section{Ethical Considerations}

This is a "service review" of published data relating to CI reliability. It does not involve patient study or contact. Ethical review was not necessary.

\section{Results}

\section{The Failure Characteristic Relating to Explantation}

Applying the study length (SL) correction factor to those clinical studies reporting overall explantation percentages gave the results shown in Fig. 2. Also shown are the results from a number of studies where explantations can be located either to a specific time frame post implantation or
Fig. 1 Effect of patient recruitment over the course of a study ('staggered-entry')—-see "Appendix 1". For example, for a 12 year implantation period results based upon the overall number of explantations need to be multiplied by a factor of 2.5 $(1 / 0.4)$ to obtain explantations in patient time. That is, using simple 'overall' incidence figures significantly underestimates the failure rate

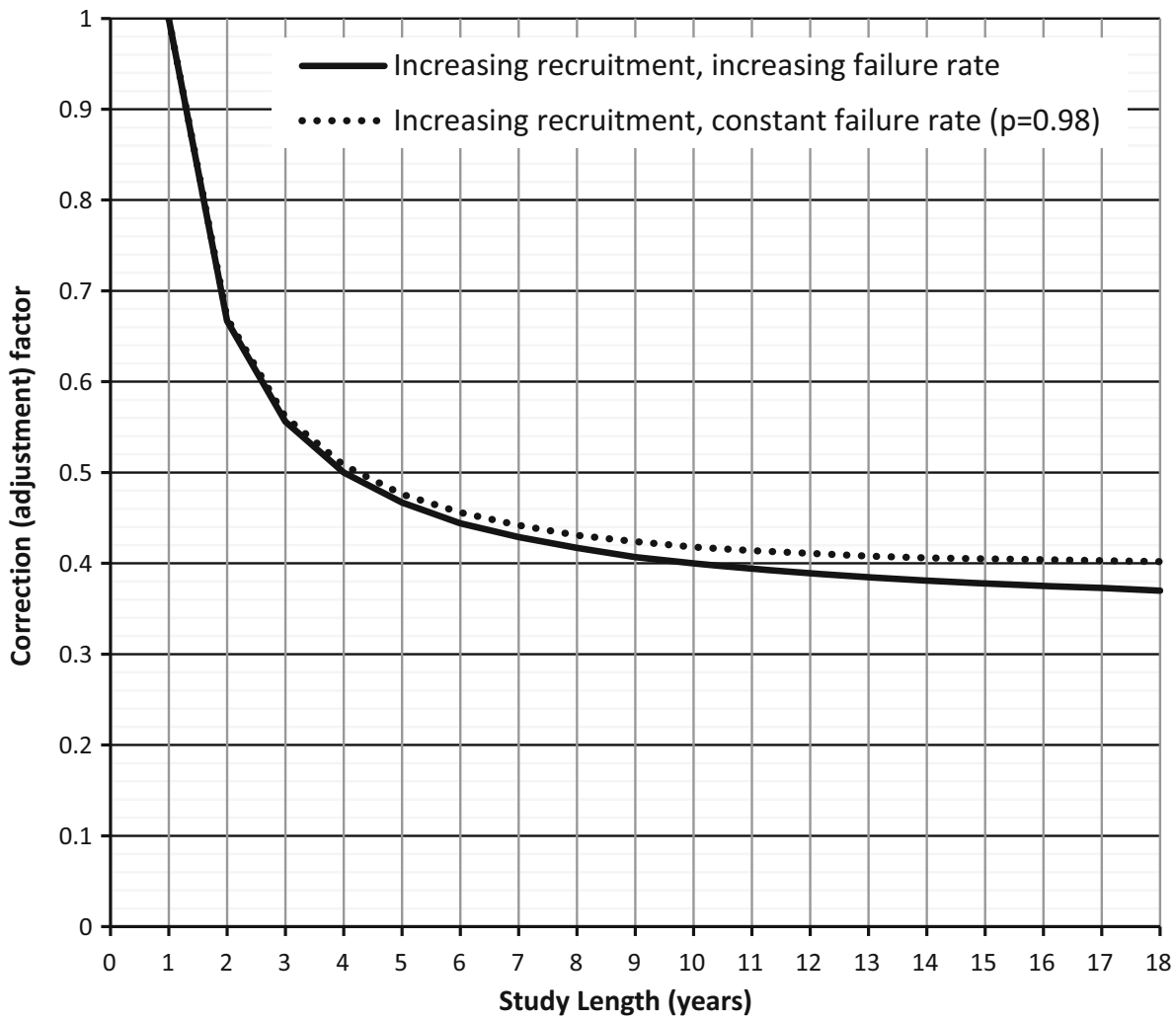




\section{SL EXPLANTATIONS \%}

(yrs) Overall Adjusted

\begin{tabular}{|c|c|c|c|}
\hline 0.5 & $0.5 \mathrm{f}-\mathrm{u}$ & 0.5 & Sorrentino ${ }^{26}$ \\
\hline 1 & $2.2 \mathrm{f}-\mathrm{u}$ & 2.2 & Alexiades ${ }^{15}$ \\
\hline 1.5 & $5.6 f-u$ & & Waltzman ${ }^{27}$ \\
\hline 2 & $3.8 f-u$ & & Francis $^{16}$ \\
\hline 2.1 & $3.3 \mathrm{f}-\mathrm{u}$ & & Moberley $^{28}$ \\
\hline 2.7 & $5.7 \mathrm{f}-\mathrm{u}$ & & Roland $^{29}$ \\
\hline 5 & 3.1 & 6.7 & Postelmans ${ }^{30}$ \\
\hline 5 & 2.3 & 4.9 & Orhan $^{31}$ \\
\hline 5 & 4.3 & 9.2 & Davids ${ }^{32}$ \\
\hline 6 & 9.7 & 21.8 & Kandogan $^{33}$ \\
\hline 6 & 6.2 & 14.0 & NOTTS ${ }^{34}$ \\
\hline 7 & 10.7 & 24.9 & Black $^{35}$ \\
\hline 7 & 4.4 & 10.3 & Balakina $^{36}$ \\
\hline 7.4 & \multicolumn{2}{|c|}{$11.1 \mathrm{f}-\mathrm{u}$} & Waltzman ${ }^{37}$ \\
\hline 9 & 17.2 & 42.3 & Arnoldner ${ }^{38}$ \\
\hline 9 & 11.2 & 27.5 & Maurer ${ }^{39}$ \\
\hline 11 & 8.1 & 20.6 & Achiques $^{40}$ \\
\hline 11 & 9.1 & 23.1 & Luetje $^{41}$ \\
\hline 11.7 & \multicolumn{2}{|c|}{$13.4 \mathrm{f}-\mathrm{u}$} & Uziel $^{42}$ \\
\hline 12 & 9.2 & 23.7 & Raine $^{43}$ \\
\hline 12 & \multicolumn{2}{|c|}{$32.3 \mathrm{f}-\mathrm{u}$} & Beadle ${ }^{44}$ \\
\hline 12 & 8.8 & 22.6 & Bertram ${ }^{45}$ \\
\hline 13 & 8.9 & 23.1 & Migirov $^{46,47}$ \\
\hline 14 & 6.6 & 17.4 & Stefanescu ${ }^{48}$ \\
\hline 14 & 8.9 & 23.4 & Cullen $^{17}$ \\
\hline 14 & 6.5 & 17.1 & Brown $^{49}$ \\
\hline 15 & 9.5 & 25.1 & $\operatorname{Lin}^{50}$ \\
\hline 15 & 12.9 & 34.1 & Marlowe ${ }^{51}$ \\
\hline 17 & 8.4 & 22.5 & Venail $^{18}$ \\
\hline 17 & 15.4 & 41.3 & Gosepath $^{52}$ \\
\hline
\end{tabular}

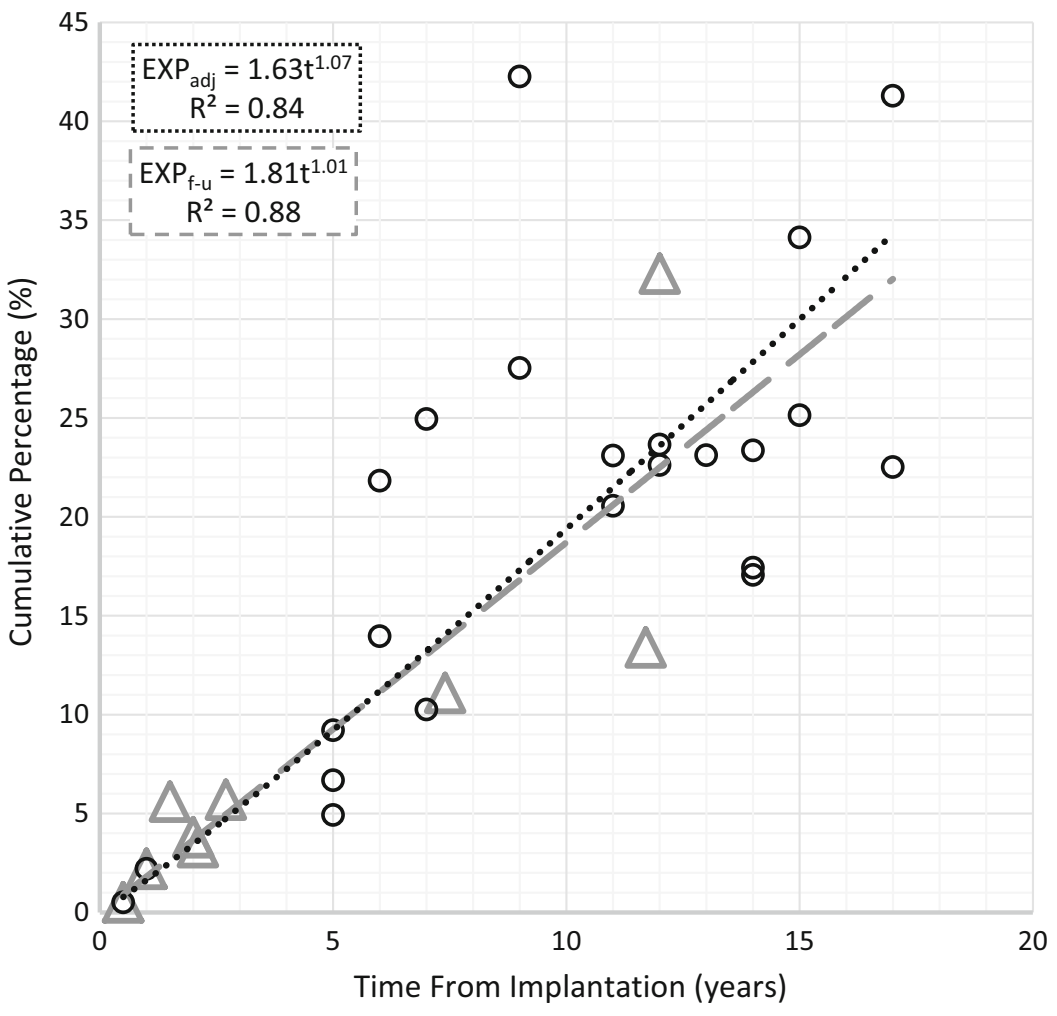

Fig. 2 Assessment of cumulative percentage for explantations (children): Triangles: nine follow-up studies $(f-u)$. Circles: Twentythree studies (adj) reporting 'overall' figures. The latter having been adjusted for 'staggerd-entry'. The difference between the two

to an approximate follow-up period. Using all the data points gives the relationship:

$\operatorname{EXP}_{c}(t)=1.88 \times t^{1.01}($ correlation coefficient $=0.84)$

The relationship is indicative of an increasing failure rate (decreasing reliability) over time. For unilateral implants, at 10 years post-implantation $19 \%$ of children will have undergone surgery involving explantation, with or without reimplantation.

\section{The Failure Characteristic Relating to Surgery Without Explantation}

This was determined by first considering the contribution of explantation to overall revision for different study methods for estimation of cumulative explantations at 10 years post-implantation is less than $5 \%(18.5 \% \mathrm{cf} 19.2 \%)$. Use of all the data gives a figure of $19.2 \%$

lengths. Explantations make up about 50\% of revision surgery over the short term increasing to about $80 \%$ over the long term. From Eq. 1, given that

$S U R_{c}(t)=E X P_{c}(t)\left[\left\{\frac{E X P_{c}(t)}{R E V_{c}(t)}\right\}^{-1}-1\right]$

cumulative surgery without device explantation was estimated from data at several time periods. The relevant data and calculations are shown in Table 1. The corresponding two-parameter Weibull curve fit, shown in Fig. 3, is of the form:-

$$
\begin{aligned}
& \operatorname{SUR}_{c}(t)=100\left[1-\exp \left\{-(\alpha t)^{\beta}\right\}\right] \text { where } \\
& \alpha=1.78 \times 10^{-3} \text { and } \beta=0.57
\end{aligned}
$$


Table 1 Cochlear implants (children)—estimation of revision surgery which does not involve device explantation SURc(t)

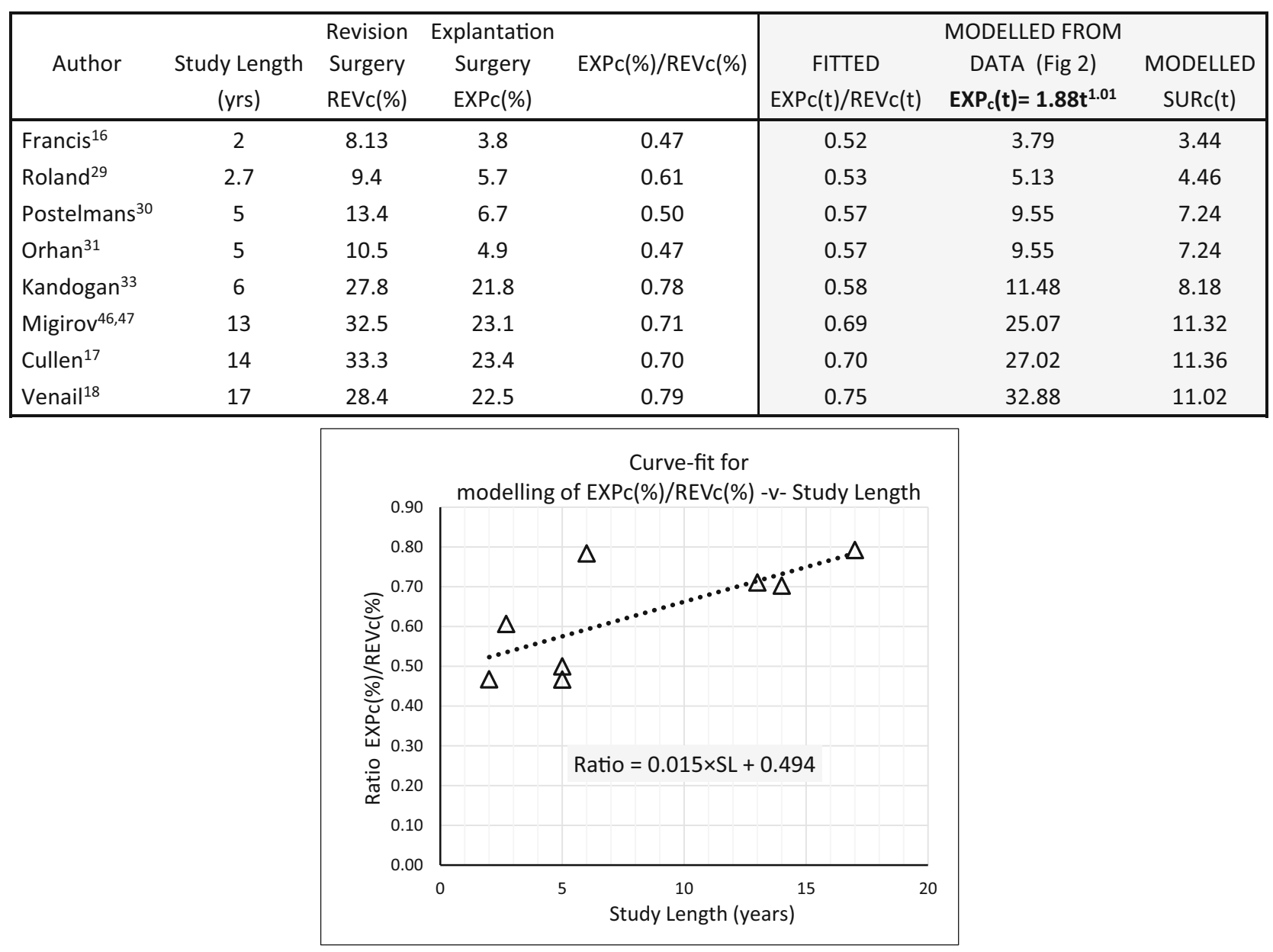

The ratio of $\operatorname{EXP}_{c}(\%) / \operatorname{REV}_{c}(\%)$ was evaluated for each of the studies above. The relationship between this ratio and study period was obtained by a curve-fit as shown in the graph. The resulting linear equation was then used to model EXP $(t) / \operatorname{REV}_{c}(t)$ (fitted) at the respective study lengths. These fitted values were then used in the equation: $\operatorname{SUR}_{c}(t)=\operatorname{EXP}_{c}(t)\left[\left\{\operatorname{EXP}_{c}(t) / \operatorname{REV}_{c}(t)\right\}^{-1}-1\right]$ (see text), to provide a modelled estimate for $\operatorname{SUR}_{\mathrm{c}}(\mathrm{t})$

In contrast to surgery involving device explantation this reflects a decreasing failure rate with respect to time $(\beta<1)$. Using the same example as above, at 10 years post-implantation about $10 \%$ of children will have undergone surgery without device explantation.

\section{The Failure Characteristic Relating to (All-Cause) Revision Surgery}

Figure 3 shows cumulative revision surgery obtained from the analyses above. At 10 years post-implantation close to $30 \%$ of children with unilateral implants will have undergone revision surgery. Clearly, this figure is considerably greater than that commonly reported for overall revision rates and illustrates the importance of interpreting results with respect to the relevant time frame.

\section{Non-Use}

From Raine et al. [13] and Contrera et al. [14] we modeled the better results (lower non-use) of the latter and used a failure rate of $1.2 \%$ year $^{-1}$. Over 10 years the cumulative survival probability is $(1-0.012 \times 10)=0.88$. That is, if the failure rate is $f_{r}(=0.012)$, then the cumulative survival probability $R(t)_{n-u}=\left(1-f_{r} \times t\right)$. 


\begin{tabular}{|c|c|c|c|}
\hline & \multicolumn{3}{|c|}{ Cumulative Percentages } \\
\hline$t$ (yrs) & SURc(t)\% & $\operatorname{EXPc}(t) \%$ & $\operatorname{REVC}(\mathrm{t}) \%$ \\
\hline 0 & 0 & 0 & 0 \\
\hline 1 & 2.7 & 1.9 & 4.5 \\
\hline 2 & 3.9 & 3.8 & 7.7 \\
\hline 2.7 & 4.7 & 5.1 & 9.8 \\
\hline 3 & 4.9 & 5.7 & 10.6 \\
\hline 4 & 5.8 & 7.6 & 13.4 \\
\hline 5 & 6.5 & 9.6 & 16.1 \\
\hline 5 & 6.5 & 9.6 & 16.1 \\
\hline 6 & 7.2 & 11.5 & 18.7 \\
\hline 7 & 7.9 & 13.4 & 21.3 \\
\hline 8 & 8.5 & 15.4 & 23.8 \\
\hline 9 & 9.0 & 17.3 & 26.3 \\
\hline 10 & 9.6 & 19.2 & 28.8 \\
\hline 11 & 10.1 & 21.2 & 31.2 \\
\hline 12 & 10.6 & 23.1 & 33.7 \\
\hline 13 & 11.0 & 25.1 & 36.1 \\
\hline 14 & 11.5 & 27.0 & 38.5 \\
\hline 14 & 11.5 & 27.0 & 38.5 \\
\hline 15 & 11.9 & 29.0 & 40.9 \\
\hline 16 & 12.3 & 30.9 & 43.2 \\
\hline 17 & 12.7 & 32.9 & 45.6 \\
\hline \multirow[t]{3}{*}{18} & 13.1 & 34.8 & 47.9 \\
\hline & & \multicolumn{2}{|c|}{$\operatorname{Exp}_{c}(t)=1.88 \mathrm{t}^{1.01}$} \\
\hline & $S U R_{c}(t)$ & $=100[$ & $\left.1-\exp \left\{-(\alpha t)^{\beta}\right\}\right]$ \\
\hline
\end{tabular}

Fig. 3 Components of cochlear implant revision surgery (children). $\operatorname{REVc}(\mathrm{t})$-Cumulative 'all-cause' revision surgery $=\operatorname{EXPc}(\mathrm{t})+$ $\operatorname{SURc}(\mathrm{t}) ; \operatorname{EXPc}(\mathrm{t})$ - Cumulative surgery involving device explantation; SURc(t)—Cumulative surgery involving everything other than

\section{Reliability Curve}

The components described above can be combined to provide a conventional reliability (survival) curve. Using the term $F(t)$ to represent the failure, or unreliability, function in the form of $\operatorname{REV}_{\mathrm{c}}(\mathrm{t})$ in Eq. 1, but without being expressed as a percentage then, for values of $\operatorname{REV}_{c}(t)$ between 0 and $100 \%, F(t)$ will have corresponding values between 0 and 1.0. The reliability (survival) probability $R(t)$ is then $R(t)=1-F(t)$. In Fig. 4, $R(t)$ is plotted vertically and takes on values between 1.0 (100\% reliability at time $\mathrm{t}=0$, i.e. no failures) and 0 (all cases have experienced failure). The abscissa is patient time in years. When incorporating non-use into this analysis we multiplied explantation (Weibull curve fit). At 10 years post-implantaion, 'allcause' revision surgery is 29\%; SURdata-Clinical data which has been transformed to cumulative values (see Table 1)

reliability (survival) probabilities on the evidence that some non-users would also have undergone explantation.

\section{Device Failure Rate}

Clinical papers report, on average, that device failures constitute about $80 \%$ of explantations [15-18], giving a failure of about $15 \%$ over 10 years of implant use (cumulative survival probability $=0.85$ ). This contrasts dramatically with figures quoted by manufacturers. A point well made by Roby et al. [19]. 


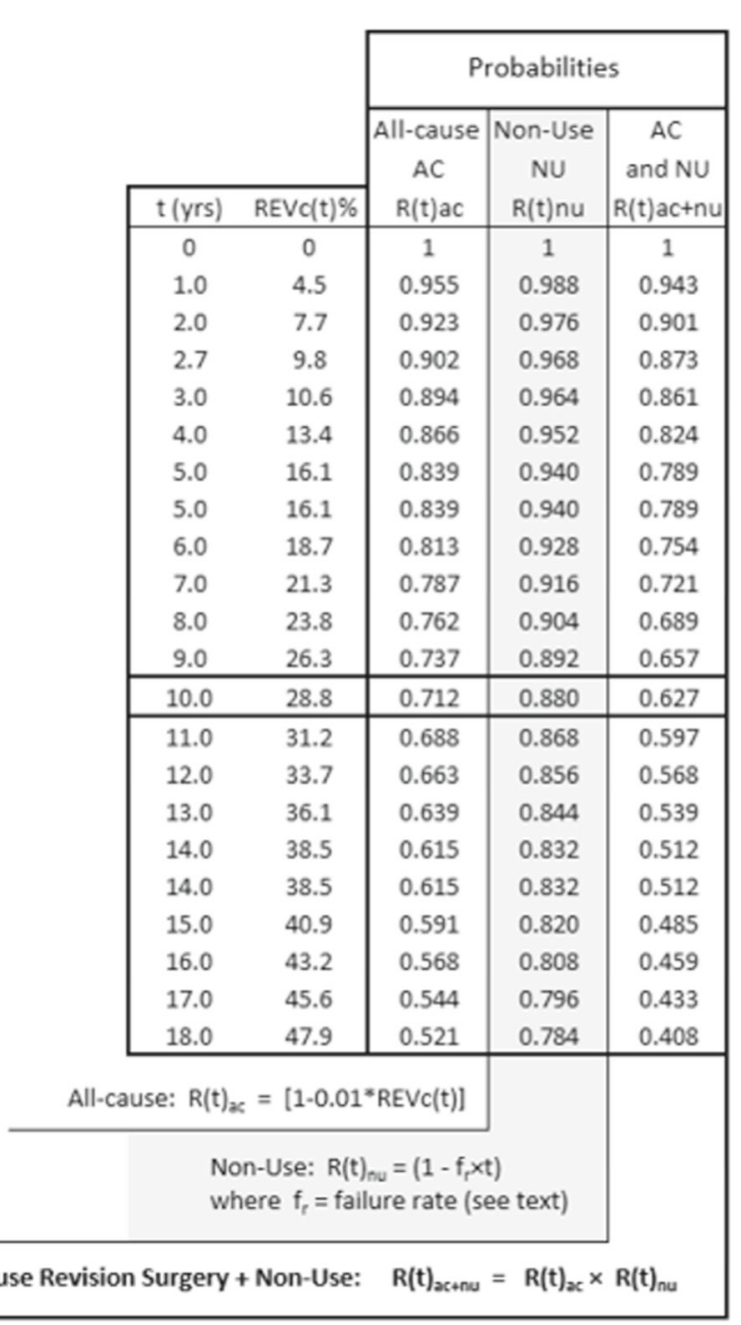

Fig. 4 Unilateral cochlear implant reliability curve. At 10 years postimplantation: $\mathrm{R}(\mathrm{t})$ for all-cause revision surgery is approx. 0.7. Since failure (un-reliability) $\mathrm{F}(\mathrm{t})=1-\mathrm{R}(\mathrm{t})=0.3$, then $30 \%$ of original patients, implanted at time $t=0$, have experienced failure. $R(t)$ for

\section{Discussion}

Cochlear implantation is described in the literature as a safe and reliable intervention for severe-to-profound bilateral sensorineural hearing loss. In particular, descriptions refer to low overall revision rates (often with no reference to a time frame) and to device reliability with survival percentages frequently quoted in the high $90 \mathrm{~s}$. The results of this present study give reason to challenge these descriptions. Firstly, regarding revision surgery, there is a very significant difference in the figures where the simple overall percentage grossly underestimates the more representative cumulative value as measured in patient time. Secondly, whereas manufacturer's data sheets for device reliability at, say, 10 years quote cumulative survival percentages (CSP) of $94 \%$ and above (cumulative failure of $\leq 6 \%$ ), clinical results indicate values in the region of $85 \%$ (cumulative failure of $\simeq 15 \%$ ). That is,

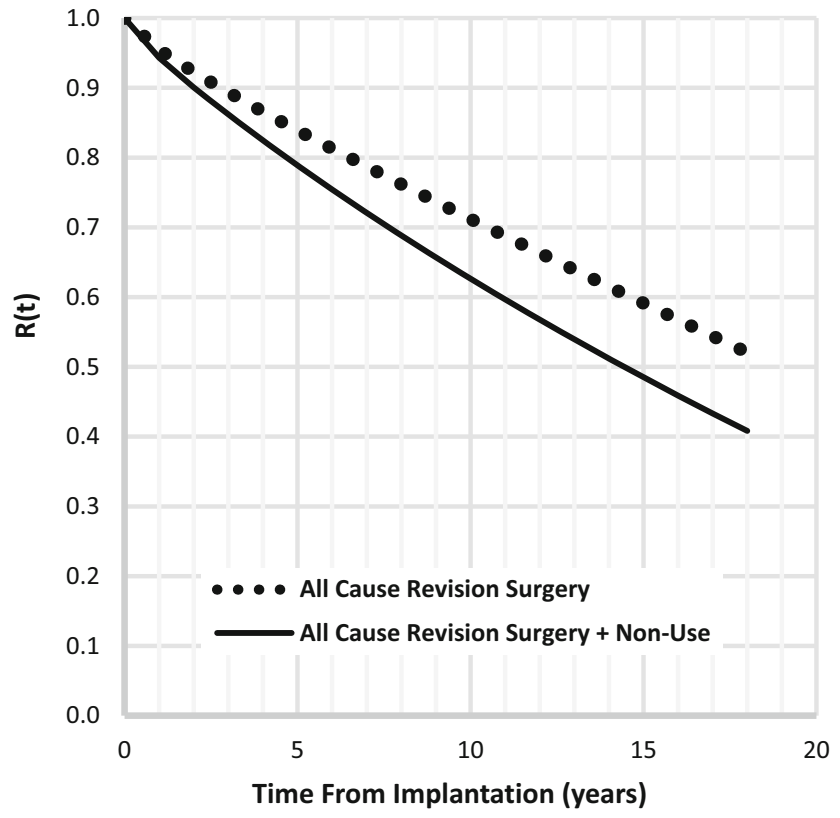

all-cause revision surgery + non-use is 0.63 . i.e. $\mathrm{F}(\mathrm{t})=0.37$ or $37 \%$ of original patients have experienced failure involving revision surgery and/or non-use

from a clinical perspective, device failure rates appear to be about three times greater than those reported by the manufacturers. Clearly, large numbers of children undergoing explant surgery do not show up as failures. Also, non-users with implanted devices within specification are not counted as failures neither are those who undergo revision surgery without device explantation. Thus, current figures for surgery and for device reliability distort the magnitude of risk. We contend that the most relevant information for parents and patients is the cumulative all-cause revision surgery (\%) over, typically, 10 years. Given that this figure is close to $30 \%$ for unilateral implants the consequences for bilateral implantation are clear. We believe that non-use should also be considered a failure since the implant is, in essence, ineffective compared to its intended purpose. Expanding upon some of the issues described above:- 


\section{Non-reporting of Numbers of 'Explantation Without Reimplantation'}

Either for medical reasons or by choice, some patients undergo explantation without reimplantation. In the few studies (four) which contained the relevant information, we found that relying upon the reported number of reimplantations underestimated the total number of explantations by about $10 \%$ (median $10.3 \%$, range $6.7-11.1 \%$ ).

\section{Patients 'Lost-to-Follow-Up’ (LTFU)}

Of the original numbers in the Contrera et al. [14] study, at 10 years post-implantation, $25 \%$ were either 'lost-to-follow-up' (15\%) or non or not regular users (10\%). Taking a value mid-way between the best and worst case scenarios (no/all LTFU being non or low users) provides an estimate of $18 \%$ of the original patients being non or low users at 10 years following implantation. Also, it is clear from this study that those 'lost-to-follow-up' and those who are 'known non-users' are not random subsets of the total group. Not taking account of this inevitably results in an underestimate of the failure rate. Our suggestion of incorporating non-use (1.2\% year ${ }^{-1}$ — see 'Results' above) with all-cause revision surgery is more accurately a metric of 'failure'.

\section{Results from Long Study Periods}

Long study periods are by default more recent publications. It is evident that higher numbers of both children and children receiving bilateral implants occur in the later study period [20-22] (only unilateral implants were provided up to the early 2000s). With this 'implants - $\mathrm{v}$ - time' profile the results of such studies will be biased by the large number of newer implants with a short duration of use even when total study length is 20 years or more. The combined effects of this with significant 'lost-to-follow-up' numbers, as described above can result in erroneous failure rates being quoted.

\section{A Simple Check}

During the earlier years of cochlear implantation a reasonable 'first approximation' of reliability could have been carried out by assuming a constant implantation rate per year for the study period and multiplying the overall revision rate by 2 (average duration of use = half the study length). Indeed, Fig. 2 includes eight studies, all published before the NICE [10] submission, where this simple check (for explantations) results in a mean of $2.4 \%$ year $^{-1}$ (median $=2.3 \%$ year $^{-1}$ ). There are also four follow-up studies giving mean and median values of $2.5 \%$ year $^{-1}$. This contrasts with an annual re-implantation rate of $0.6 \%$ quoted in support of implantation (NICE [10-p31]).

\section{Cochlear Implants and Unilateral Hearing Loss}

Being aware that implantation is also being promoted for unilateral/asymmetrical hearing loss, we would agree with The American Speech-Language-Hearing Association [23]_ 'A cochlear implant is not an option for children with Unilateral Hearing Loss. This device, which is placed surgically in the inner ear, is only for children with severe or profound hearing loss in both ears'. This contrasts sharply with information leaflets which describe the possibility of implants providing help for single-sided deafness in a variety of situations, including the classroom [24, 25]. Given the information provided in this paper we see no sound basis for the promotion of implants for single-sided deafness.

\section{Strengths and Limitations of this Study}

The main strength of the study is that of results from a relatively large number of children $(>6300)$ combined with an appropriate measurement statistic for staggeredentry design. The main limitation relates to the data available for the analysis in that some studies were more comprehensive and/or specific than others on the reasons for revision surgery. Therefore, and in common with other branches of medicine, there is a high likelihood of underreporting in several of the studies.

\section{Compliance with Ethical Standards}

Conflict of interest The authors declare that they have no conflict of interest.

Open Access This article is licensed under a Creative Commons Attribution 4.0 International License, which permits use, sharing, adaptation, distribution and reproduction in any medium or format, as long as you give appropriate credit to the original author(s) and the source, provide a link to the Creative Commons licence, and indicate if changes were made. The images or other third party material in this article are included in the article's Creative Commons licence, unless indicated otherwise in a credit line to the material. If material is not included in the article's Creative Commons licence and your intended use is not permitted by statutory regulation or exceeds the permitted use, you will need to obtain permission directly from the copyright holder. To view a copy of this licence, visit http://creativecommons. org/licenses/by/4.0/. 


\section{Appendix 1}

\section{Effect of Patient Recruitment Throughout a Study ('Staggered-Entry')}

\section{Constant Failure Rate}

For increasing recruitment numbers per year, let $n_{i}=i \times k$ where $\mathrm{k}=$ constant

Also, for a constant failure rate, conditional probability $\mathrm{p}=$ constant.

Total number of explants for say a three year study length

$(\mathrm{SL}=3)=\mathrm{n}_{1}\left(1-\mathrm{p}^{3}\right)+\mathrm{n}_{2}\left(1-\mathrm{p}^{2}\right)+\mathrm{n}_{3}\left(1-\mathrm{p}^{1}\right)$

Total number of implants $=\mathrm{n}_{1}+\mathrm{n}_{2}+\mathrm{n}_{3}=1 \mathrm{k}+2 \mathrm{k}+3 \mathrm{k}$

$=\mathrm{k} \times \mathrm{L}$

where $\mathrm{L}=\sum_{z=1}^{S L}(\mathrm{z})$

Thus,

$\operatorname{EXP}_{c}(3)=\frac{\left\{1\left(1-\mathrm{p}^{3}\right)+2\left(1-\mathrm{p}^{2}\right)+3\left(1-\mathrm{p}^{1}\right)\right\}}{\mathrm{L}} \times 100$

In general, $\quad \operatorname{EXP}_{c}(\mathrm{SL})=\frac{100}{\mathrm{~L}} \sum_{i=1, j=S L}^{S L, 1} \mathrm{i}\left(1-p^{j}\right)$

For all implantations at $\mathrm{t}=0$,

$\operatorname{EXP}_{\mathrm{c}}(\mathrm{SL})=100 \times\left(1-\mathrm{p}^{\mathrm{SL}}\right)$

Thus, the ratio $\frac{\text { successive implantation }}{\text { all implantations at time } t=0}$

$$
=\frac{1}{\left(1-p^{S L}\right) \mathrm{L}} \sum_{i=1, j=S L}^{S L, 1} \mathrm{i}\left(1-p^{j}\right) .
$$

\section{Increasing Failure Rate}

For increasing recruitment numbers per year, let $n_{i}=i \times k$ where $\mathrm{k}=$ constant.

If number of explantations per year for each $n_{i}$ is the same $=\mathrm{C} \times \mathrm{n}_{\mathrm{i}}$ where $\mathrm{C}$ is a constant.

Total number of explants for say a three year study length

$(\mathrm{SL}=3)=\mathrm{C} \times \mathrm{n}_{1} \times 3+\mathrm{C} \times \mathrm{n}_{2} \times 2+\mathrm{C} \times \mathrm{n}_{3} \times 1$

$=\mathrm{C} . \mathrm{k}(1 \times 3+2 \times 2+3 \times 1)$

Total number of implants $=\mathrm{n}_{1}+\mathrm{n}_{2}+\mathrm{n}_{3}=1 \mathrm{k}+2 \mathrm{k}+3 \mathrm{k}$

$=\mathrm{k} \times \mathrm{L}$

where $\mathrm{L}=\sum_{z=1}^{S L}(\mathrm{z})$
In general, $\quad \operatorname{EXP}_{c}(\mathrm{SL})=\frac{100 \times \mathrm{C}}{\mathrm{L}} \sum_{i=1, j=S L}^{S L, 1} \mathrm{i} \times \mathrm{j}$

For all implantations at $\mathrm{t}=0$,

$\operatorname{EXP}_{c}(\mathrm{SL})=100 \times \mathrm{C} \times \mathrm{SL}$

Thus, the ratio $\frac{\text { successive implantation }}{\text { all implantations at time } t=0}$

$$
=\frac{1}{\mathrm{SL} \times \mathrm{L}} \sum_{i=1, j=S L}^{S L, 1} \mathrm{i} \times \mathrm{j} .
$$

This ratio, for study lengths ranging from 1 to 18 years, is shown graphically in Fig. 1.

\section{References}

1. Borovkova S (2002) Analysis of survival data. NAW 3:302-307

2. Murray DW, Britton AR, Bulstrode CJK (1997) Loss to followup matters. J Bone Joint Surg [Br] 79B:254-257

3. Murray DW, Carr AJ, Bulstrode C (1993) Survival analysis of joint replacements. J Bone Joint Surg 75B(5):697-704

4. Leitch JW, Dear K, Curteis P (1994) Upward bias in estimates of pacemaker reliability: effect of unreported patient mortality. JACC 24(4):1078-1081

5. EURO (2005) European consensus statement on cochlear implant failures and explantations. Otol Neurotol 26(6):1097-1099

6. Muller J, Sudhoff H, Hildmann H (2006) Revision surgery after cochlear implantation. In: Hildmann S (ed) Middle ear surgery. Springer, Berlin, p 153

7. Wang JT, Wang AY, Psarros C, DaCruz M (2014) Rates of revision and device failure in cochlear implant surgery: a 30-year experience. Laryngoscope 124(10):2393-2399. https://doi.org/ 10.1002/lary.24649

8. Shih WJ (2002) Problems in dealing with missing data and informative censoring in clinical trials. Curr Control Trials Cardiovasc Med 3(1):4. https://doi.org/10.1186/1468-6708-3-4

9. Gorouhi F, Khatami A, Davari P (2009) A neglected issue in interpretation of results of randomized controlled trials: informative censoring. Dermatol Online J 15(1). https://escholar ship.org/uc/item/3b5381b2

10. NICE 2007 Health Technology Appraisal. Cochlear implants for deafness in children and adults, a joint submission on behalf of British Academy of Audiology, British Cochlear Implant Group, ENT UK

11. Fitzpatrick EM, Brewster L (2010) Adult cochlear implantation in Canada: results of a survey. Rev Can Ortho d'audiol 34(4):290-296

12. Zeng FG, Rebscher S, Harrison WV, Sun X, Feng H (2008) Cochlear implants: system design, integration and evaluation. IEEE Rev Biomed Eng 1:115-142. https://doi.org/10.1109/ RBME.2008.2008250

13. Raine CH, Summerfield Q, Strachan DR, Martin JM, Totten C (2008) The cost and analysis of nonuse of cochlear implants. Otol Neurol 29:221-224. https://doi.org/10.1097/mao.0b013e3181 $5 \mathrm{c} 25 \mathrm{a} 1$

14. Contrera KJ, Choi JS, Blake CR, Betz JF, Niparko JK, Lin FR (2014) Rates of long-term cochlear implant use in children. Otol Neurotol 35(3):426-430. https://doi.org/10.1097/MAO.0000000 000000243 
15. Alexiades G, Roland JT, Fishman AJ, Shapiro W, Waltzman S, Cohen NL (2001) Cochlear reimplantation: surgical techniques and functional results. Laryngoscope 111:1608-1613

16. Francis HW, Buchman CA, Visaya JM, Wang N-Y, Zwolan TA, Fink NE, The CDaCI Inv. Team, Niparko J (2008) Surgical factors in pediatric cochlear implantation and their early effects on electrode activation and functional outcomes. Otol Neurotol 29:502-508. https://doi.org/10.1097/MAO.0b013e318170b60b

17. Cullen RD, Fayad JN, Luxford WM, Buchman CA (2008) Revision cochlear implant surgery in children. Otol Neurol 29:214-220

18. Venail F, Sicard M, Piron JP, Levi A, Artieres F, Uziel A, Mondain M (2008) Reliability and complications of 500 consecutive cochlear implantations. Arch Otolaryngol Head Neck Surg 124(12):1276-1281

19. Roby BB, Ferrello M, Huang TC, Rimell FL, Levine SC (2012) Symptom timeline preceding cochlear implant failure. Otolaryngol Head Neck Surg 146(5):782-787. https://doi.org/10.1177/ 0194599811434272

20. Eskander A, Gordon KA, Kadhim L, Papaioannou V, Cushing SL, James AL, Papsin BC (2011) Low pediatric cochlear implant failure rate contributing factors in large-volume practice. Arch Otolaryngol Head Neck Surg 137(12):1190-1196

21. Masterson L, Kumar S, Kong JHK, Briggs J, Donnelly N, Axon PR, Gray RT (2012) Cochlear implant failures: lessons learned from a UK centre. J Laryngol Otol 126:15-21

22. Trozzi M, Powell HRF, Toma S, Ahmed W, Jephson CG, Rajput $\mathrm{K}$, Cochrane LA (2015) Cochlear re-implant rates in children: 20 years experience in a quaternary paediatric cochlear implant centre. Eur Arch Otorhinolaryngol 272:2667-2672. https://doi. org/10.1007/s00405-014-3206-0

23. American Speech-Language-Hearing Association-ASHA (2017) Unilateral hearing loss in children

24. Ear Foundation, Nottingham, UK (2011) What about those with single-sided deafness? Cochlear Implant Information Sheet

25. Ear Foundation, Nottingham, UK (2016) Those with hearing only in one ear. Cochlear Implant Information Sheet

26. Sorrentino T, Cote M, Eter E, Laborde ML, Cochard N, Deguine O, Fraysse B (2009) Cochlear re-implantations: technical and surgical failures. Acta Otolaryngol 129:380-384

27. Waltzman SB, Roland T (2005) Cochlear implantation in children younger than 12 months. Pediatrics 116(4):e487-e493

28. Moberly AC, Welling DB, Nittrouer S (2013) Detecting soft failures in pediatric cochlear implants: relating behavior to language outcomes. Otol Neurotol 34(9):1648-1655. https://doi.org/ 10.1097/MAO.0b013e3182a0036c

29. Roland JT, Cosetti M, Wang KH, Immerman S, Waltzman SB (2009) Cochlear implantation in the very young child: long-term safety and efficacy. Laryngoscope 119(11):2205-2210. https://doi.org/ 10.1002/lary.20489

30. Postelmans J (2012) Cochlear implantation: surgical and audiological assessment of cochlear implantation techniques. Chapter 2 post-operative complications of cochlear implantation in adults and children: five years' experience in Maastricht. Thesis, Uni Maastricht, pp 27-39

31. Orhan KS, Guldlken Y, Basaran Ulusan M, Polat B, Cellk M, Deger K (2012) Complications and their management following pediatric cochlear implantations. Int Adv Otol 8(2):244-252

32. Davids T, Ramsden JD, Gordon KA, James AL, Papsin BC (2009) Soft tissue complications after small incision pediatric cochlear implantation. Laryngoscope 119(5):980-983. https://doi.org/10.1002/lary.20204

33. Kandogan T, Levent O, Gurol G (2005) Complications of paediatric cochlear implantation: experience in Izmir. J Laryngol Otol 119(8):606-610

34. NOTTS (1996) Appendix C, BACDA Newsletter (Oct)
35. Black B, Black J, Wallwork B (2005) Early pediatric implantation: cochlear implant surgery at the crossroads? Mediterr J Otol 1:01-10

36. Balakina A, Litvak M and Starokha A (2014) Postoperative complications in cochlear implant users: audiological outcomes and assessment of quality of life. In: 13th International conference on cochlear implants, Munich

37. Waltzman SB, Cohen NL, Green J (2002) Long-term effects of cochlear implants in children. Otolaryngol Head Neck Surg 126:505-511

38. Arnoldner C, Baumgartner WD, Gstoettner W, Hamzavil J (2005) Surgical considerations in cochlear implantation in children and adults: a review of 342 cases in Vienna. Acta Oto-Laryngol 125(3):228-234. https://doi.org/10.1080/00016480410022895

39. Maurer J, Marangos N, Ziegler E (2005) Reliability of cochlear implants. Otolaryngol Head Neck Surg 132(5):746-750

40. Achiques MT, Morant A, Munoz N, Marco J, Llopez I, Latorre E, Pitarch I (2010) Cochlear implant complications and failures. Acta Otorrinolaringol Esp 61(6):412-417

41. Luetje CM, Jackson K (1997) Cochlear implants in children: what constitutes a complication? Otolaryngol Head Neck Surg 117:243-247

42. Uziel AS, Sillon M, Vieu A, Artieres F, Piron JP, Daures JP, Mondain M (2007) Ten-year follow-up of a consecutive series of children with multichannel cochlear implants. Otol Neurotol 28(5):615-628

43. Raine CH, Strachan DR, Totten C, Martin J, Killan C, Khan S (2004) Cochlear reimplantation in adults and children. In: International congress series, vol 1273, Indianapolis, USA, pp 137-141

44. Beadle EAR, McKinley DJ, Nikolopoulos TP, Brough J, O’Donoghue GM, Archbold SM (2005) Long-term functional outcomes and academic-occupational status in implanted children after 10-14 years of Cochlear Implant Use. Otol Neurotol 26:1152-1160

45. Bertram B, Meyer V (2002) Psychological aspects of re-implantation of children from the parents' perspective. In: 6th European symposium on paediatric cochlear implantation, Las Palmas

46. Migirov L, Muchnik C, Neeman K, Kronenberg J (2006) Surgical and medical complications in paediatric cochlear implantation: a review of 300 cases. Cochlear Implants Int 7(4):194-201. https://doi.org/10.1179/cim.2006.7.4.194

47. Migirov L, Taitelbaum-Swead R, Hildesheimer M, Kronenberg J (2007) Revision surgeries in cochlear implant patients: a review of 45 cases. Eur Arch Otorhinolaryngol 264:3-7. https:// doi.org/10.1007/s00405-006-0144-5

48. Stefanescu EH, Poenaru M, Balica NC et al (2016) Reliability of med-El cochlear implants in children. The Romania experience. Int J Eng Res and Appl 6(7):25-30

49. Brown KD, Connell SS, Balkany TJ, Eshraghi AE, Telischi FF, Angeli SA (2009) Incidence and indications for revision cochlear implant surgery in adults and children. Laryngoscope 119:152-157. https://doi.org/10.1002/lary.20012

50. Lin JW, Mody A, Tonini R, Emery C, Haymond J, Vrabec JT, Oghalai JS (2010) Characteristics of malfunctioning channels in pediatric cochlear implants. Laryngoscope 120(2):399-404

51. Marlowe AL, Chinnici JE, Rivas A, Niparko JK, Francis HW (2010) Revision cochlear implant surgery in children: The Johns Hopkins Experience. Otol Neurotol 31:74-82

52. Gosepath J, Lippert K, Keilmann A, Mann WJ (2009) Analysis of fifty-six cochlear implant device failures. ORL 71:142-147. https://doi.org/10.1159/000212756

Publisher's Note Springer Nature remains neutral with regard to jurisdictional claims in published maps and institutional affiliations. 